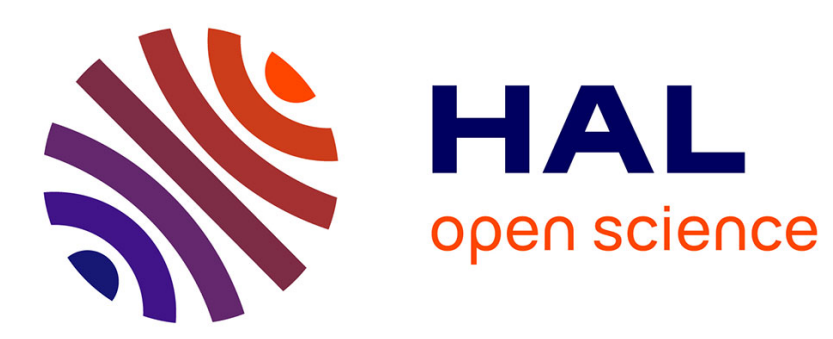

\title{
Atomic Layer-by-Layer MOCVD of Oxide Superconductors
}

S. Oda, S. Yamamoto, A. Kawaguchi

\section{To cite this version:}

S. Oda, S. Yamamoto, A. Kawaguchi. Atomic Layer-by-Layer MOCVD of Oxide Superconductors. Journal de Physique IV Proceedings, 1995, 05 (C5), pp.C5-379-C5-390. 10.1051/jphyscol:1995545 . jpa-00253907

\section{HAL Id: jpa-00253907 https://hal.science/jpa-00253907}

Submitted on 1 Jan 1995

HAL is a multi-disciplinary open access archive for the deposit and dissemination of scientific research documents, whether they are published or not. The documents may come from teaching and research institutions in France or abroad, or from public or private research centers.
L'archive ouverte pluridisciplinaire HAL, est destinée au dépôt et à la diffusion de documents scientifiques de niveau recherche, publiés ou non, émanant des établissements d'enseignement et de recherche français ou étrangers, des laboratoires publics ou privés. 


\title{
Atomic Layer-by-Layer MOCVD of Oxide Superconductors
}

\author{
S. Oda, S. Yamamoto and A. Kawaguchi
}

Research Center for Quantum Effect Electronics, Tokyo Institute of Technology, 2-12-1 O-okayama, Meguro-ku, Tokyo 152, Japan

\begin{abstract}
A very smooth surface film of c-axis oriented $\mathrm{YBa}_{2} \mathrm{Cu} 3 \mathrm{Ox}$ (YBCO) with roughness of less than monomolecular layer over $10 \mu \mathrm{mx} 10 \mu \mathrm{m}$, free of precipitates, has been obtained by atomic layer-by-layer metalorganic chemical vapor deposition (MOCVD) on a SrTiOz substrate at $650^{\circ} \mathrm{C}$. A very large terrace length of $0.3-0.5 \mu \mathrm{m}$ may be due to the enhanced migration of growing species on the surface. The result of an attempt to prepare YBCO films with a larger terrace width surface using $\mathrm{NdGaO}_{3}$ substrates is discussed. The correlation between boulder formation and dislocations in the substrate is clarified and methods for eliminating boulders are proposed. Very high superconductivity critical cursent densities of $3 \times 10^{7} \mathrm{~A} / \mathrm{cm}^{2}$ at $4.2 \mathrm{~K}$ and $3 \times 10^{6} \mathrm{~A} / \mathrm{cm}^{2}$ at $77 \mathrm{~K}$ have been obtained.
\end{abstract}

\section{INTRODUCTION}

Although pulsed laser deposition and sputtering, the most commonly used methods for deposition of thin films of high temperature superconductors (HTS), are successful in demonstrating prototype devices, there is a problem in terms of manufacturability. Various types of HTS-based Josephson junctions have been presented, including bi-crystal, step-edge, ramp-cdge and electron-beam damage junctions. Howcver, all the junctions reported are weak-link type. In spite of many attempts, nobody has successfully prepared superconductor-insulator-superconductor (S-I-S) tunnel-type junctions, which requires a very smooth sufface and conformal growth mode to make a very thin insulator free of pin-holes. MOCVD is an attractive method of deposition because it can solve the above problems. It is well regarded that MOCVD is a manufacturable technology in semiconductor industries, particularly the feature of high throughput and large area uniformity. The feature of using molecular precursor in MOCVD makes it a versatile method. Precursors can be transported for a long distance from outside of the reaction chamber, which is convenient for multiple sources for complicated materials and multilayered structure. On the other hand, multiple sources are difficult for physical vapor deposition without sacrificing uniformity or large volume chamber. The feature that chemical reaction takes place on the substrate in MOCVD is a basis for conformal grow th selective deposition and low temperature growth and is useful for the fabrication of tri-layer S-I-S tunnel devices. We have already solved the following problems of MOCVD: the problem of instability of precursors has been overcome by employing sccond generation precursors using adducts [1], and lack of in-situ monitoring method using RHEED has been compensated by optical reflectance measurements [2].

In this paper, we report additional advantages of MOCVD that a very smooth surlace and high critical currents are obtained in YBCO thin films. 


\section{EXPERIMENTAL}

Dipivaloylmethanate (DPM) compounds of metals are used as precursors. Among three metallic sources of YBCO, barium precursors caused a problem of degradation. Since the size of barium atom is large compared to ligands, barium precursors tend to form an oligomer by associating neighboring molecules resulting in less volatile complex. Phenanthroline adducts are helpful in preventing oligomerization by the effect of steric hindrance. The second generation barium precursor lasts long timc. We could prepare more than 500 samples of $\mathrm{YBCO}$ without changing the precursor, that allowed us a systematic optimization of growth conditions. The atomic layer-by-layer MOCVD apparatus, depicted in Fig. 1, consists of a gas control panel, a temperature control panel, a horizontal reactor tube made of Pyrex, a vacuum system and optical reflectance measurement system. Gas feed valves were controlled by a computer program. Sources of each atom were supplied sequentially according to the crystal structure of $\mathrm{YBCO}$. Temperatures of precursors were $110^{\circ} \mathrm{C}$ for $\mathrm{Y}(\mathrm{DPM}) 3,195^{\circ} \mathrm{C}$ for $\mathrm{Ba}(\mathrm{DPM}) 2$ (phen)2, $80^{\circ} \mathrm{C}$ for $\mathrm{Cu}(\mathrm{DPM}) 2$. Flow rate of argon carrier gas was $200 \mathrm{sccm}$. The duration periods of gas source pulse are between $30-60 \mathrm{~s}$ which is long enough compared to the residence time of gases (a few seconds) and the response time of gas fecd valves. Argon purge gas of $10 \mathrm{~s}$ was inserted between each metallic precursor in order to define the atomic layer growth clearly. $\mathrm{N}_{2} \mathrm{O}$ as an oxidizing agent was supplied continuously at a flow rate of $200 \mathrm{sccm}$. All the substrates were mechanochemichally polished. The root-mean-square roughness of the surface of the substrates were $0.14 \mathrm{~nm}$ for $\mathrm{SrTiO}_{3}, 0.73 \mathrm{~nm}$ for $\mathrm{MgO}$ and $0.09 \mathrm{~nm}$ for $\mathrm{NdGaO}_{3}$. The substrate temperature during deposition was $650^{\circ} \mathrm{C}$. Total reactor pressure was 2 Torr. The deposition rate was typically $10 \mathrm{~nm} /$ hour. After deposition was completed, the substrate temperature was decreased to $400^{\circ} \mathrm{C}$. Oxygen gas was then introduced in the reactor and kept for $10 \mathrm{~min}$., when oxygen doping was carried out to make films superconducting.

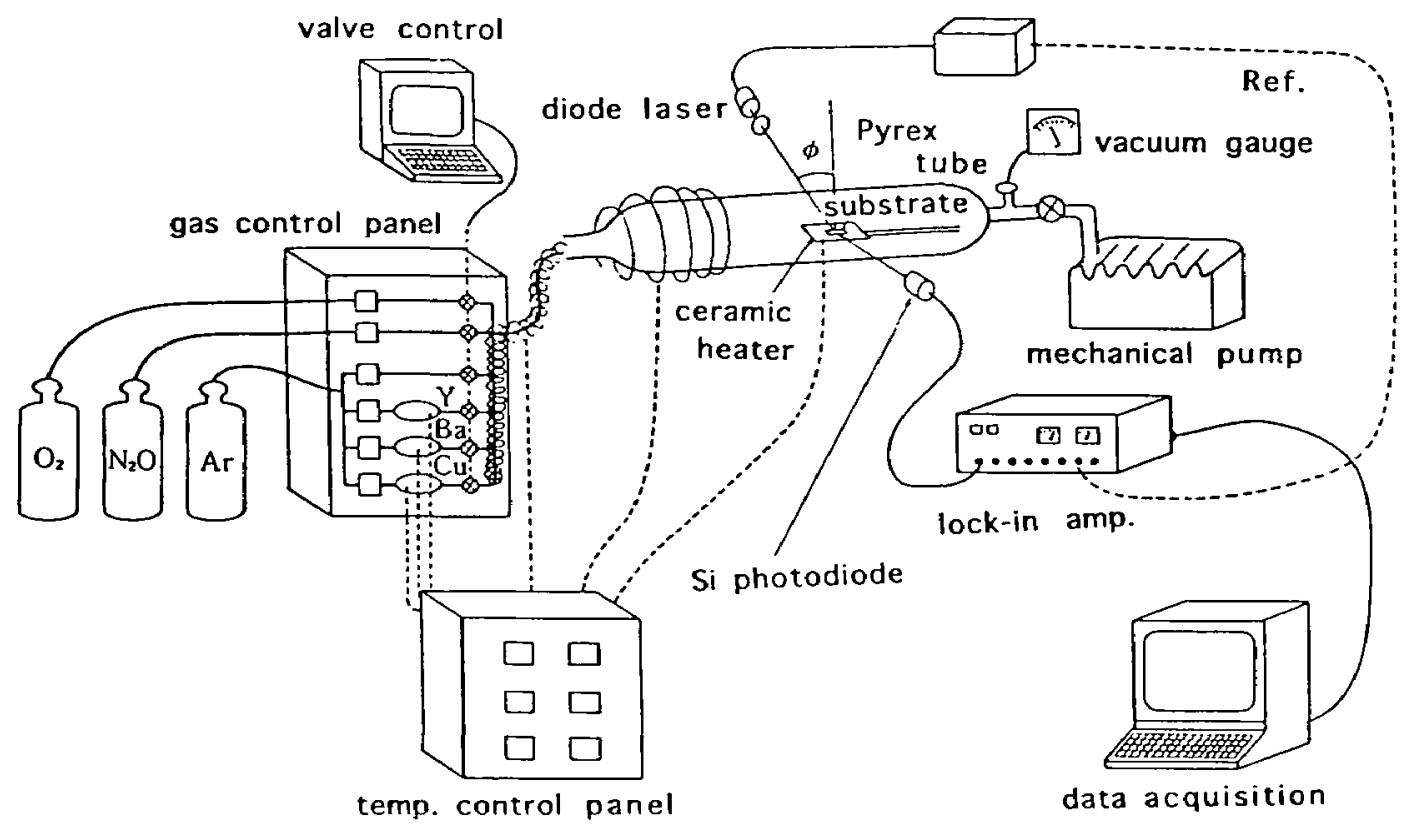

Figure 1: Schematic diagram of atomic layer-by-layer MOC (I) system for ITS fillms 


\section{RESULTS AND DISCUSSION}

The thickness of YBCO films increases linearly with cycle number of gas source supply [3]. Although the growth rate is very close to the ideal one-unit-cell per cycle line, we do not intend to claim that self-limiting mechanism is incorporated in this system. We carried out preliminary experiment of self-limiting adsorption of precursors [4]. A saturation of adsorption with flow rate of precursors was found for $\mathrm{Cu}$ at lower temperatures (around $100^{\circ} \mathrm{C}$ ). However, the surface coverage of copper atoms was less than $10 \%$ due to the steric hindrance of ligands.

Atomic force microscopy was used to observe surface morphology of YBCO films. Surface profile is characterized by steps of $1.2 \mathrm{~nm}$, which corresponds to onc unit-cell-thick of c-axis oriented YBCO films. The width of terrace between steps can be a measure of migration distance of chemical species on the surface of the substrate during deposition process. We have compared the terrace width of YBCO films prepared by atomic layer MOCVD and conventional co-deposition MOCVD where sources are supplied simultaneously. The terrace width for atomic layer MOCVD is increased from $90 \mathrm{~nm}$ to $160 \mathrm{~nm}$ in the case of $\mathrm{MgO}$ substrate and from $90 \mathrm{~nm}$ to $330 \mathrm{~nm}$ in the case of STO substrate [3]. The effect of migration cnhancement in atomic layer MOCVD is evident as is the case of flow rate modulation MOCVD in GaAs $[5]$.

Figurc 2 shows AFM images of YBCO films in the macroscopic scale, $10 \mu \mathrm{mx} 10 \mu \mathrm{m}$, which are characterized by boulders or second phase precipitates and very smooth surface of 123 system. The chemical composition of the boulders are mostly $\mathrm{CuO}$. The separation between boulders is increased significantly in atomic layer MOCVD. Migration of species for boulders is also enhanced.
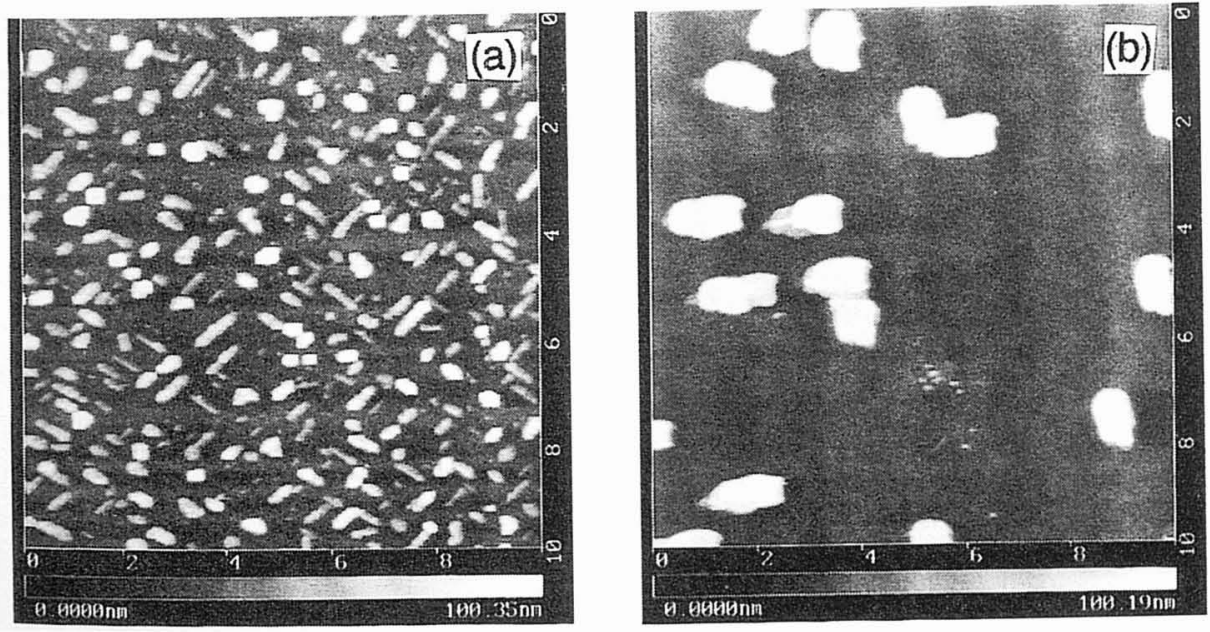

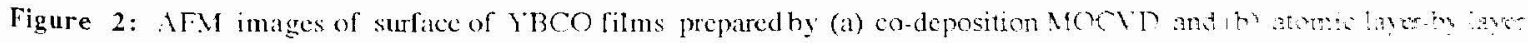
MoCD. The area is $10 \mu m \times 10 \mu m$. 
When STO substrates are etched by buffered HF solution, etch pits presumably due to dislocations of STO substrate appear in AFM images. The density of etch pits are similar to that of boulders on YBCO surface. In an attempt to clarify the correlation between the etch pits and the boulders, we prepared a patterned sample which enables us to observe the same position by AFM after etching. After etching slightly by $\mathrm{H}_{3} \mathrm{PO}_{4}$, YBCO layer was removed while the boulders are remained as shown in Fig. 3(a). It has been clarified that the boulders are grown directly from the substrate, not on YBCO layer. Further etching process removed the boulders. Etching by buffered HF manifested dislocations in STO. The positions of the boulders were exactly the same as dislocations as shown in Fig. 3(b).
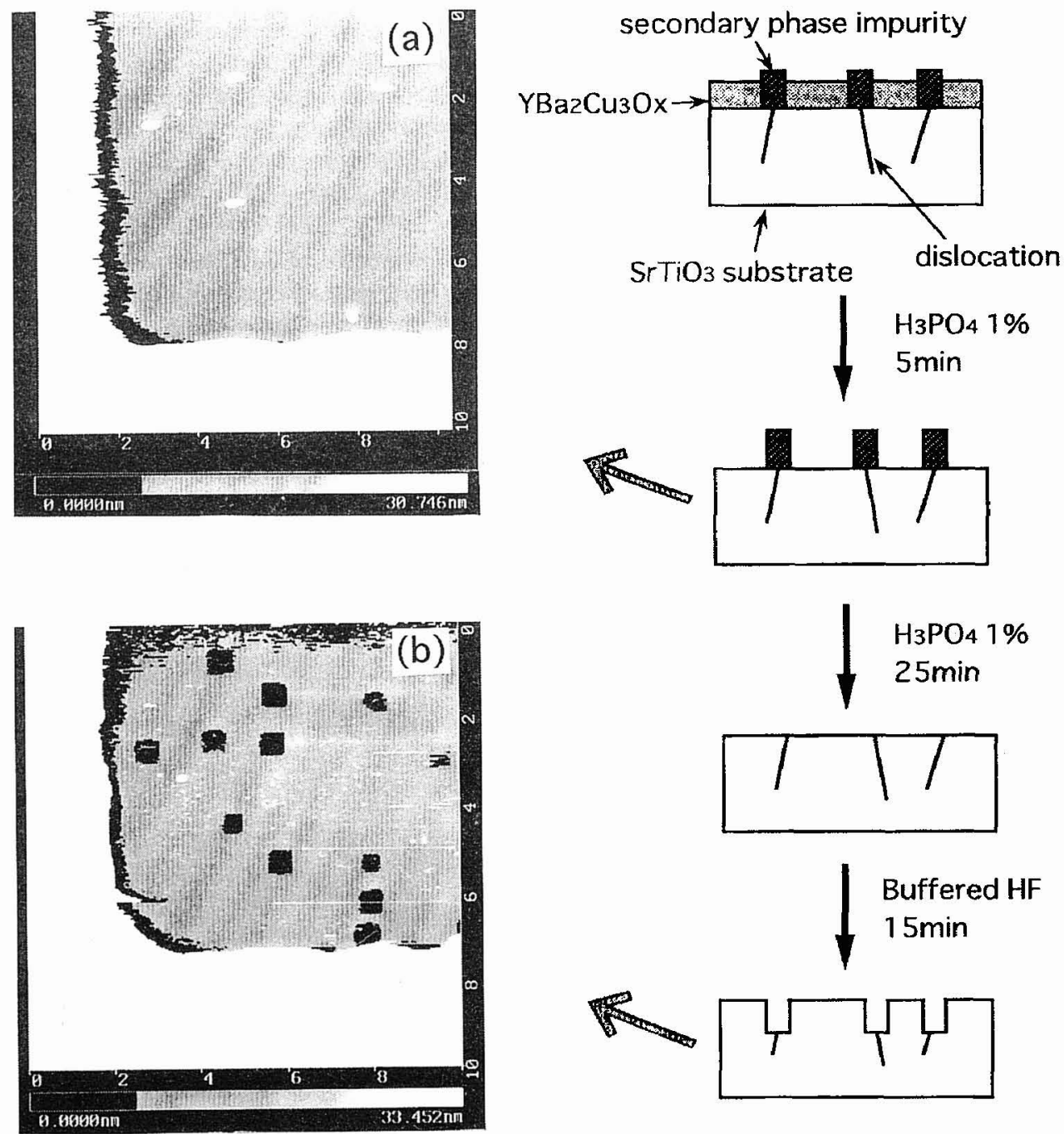

Figure 3: AFM images of surface of YBCO films prepared by atomic layer-by-layer MOCVD and pattemed by photoresists (a) after slightly etched by $\mathrm{H}_{3} \mathrm{PO}+$ solution showing boulders and (b) after etched by buffered HF solution showing etch pits. The area is $10 \mu \mathrm{mx} 10 \mu \mathrm{m}$. 
These experimental facts suggest a model of boulder formation as shown in Fig. 4. Nucleation of CuOx boulders takes place preferentially at dislocations. The growth rate of $\mathrm{CuOx}$ is much higher than that of YBCO. Then once $\mathrm{CuOx}$ is formed, $\mathrm{CuOx}$ grows epitaxially on $\mathrm{CuO}$ boulders taking away $\mathrm{Cu}$ atoms from YBCO phase. Thus, it is usually necessary to have $\mathrm{Cu}$-rich condition to obtain highly superconducting YBCO.

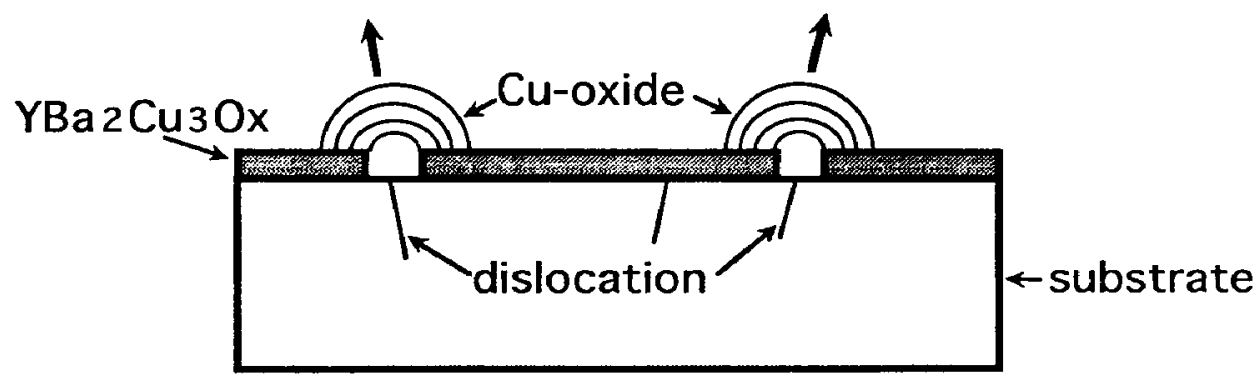

Figure 4: A schematic model for boulder formation in MOCVD of YBCO thin films.

We propose several methods to eliminate boulders as shown in Fig. 5. First, the position of boulder can be controlled by engraving artificial getter where boulder will be formed preferentially leaving free of precipitates surroundings. Second, a buffer layer of STO can eliminate the dislocation of STO substrate as the case of GaAs epitaxial layer on a GaAs substrate. Third, a buffer layer of other material is also useful. The important thing is to block the contact of $\mathrm{Cu}$ atoms to the dislocation on the substrate without sacrificing epitaxial characteristics. Finally, boulders once formed can even be swept away using STM tips. 


\section{1) Artificial getter}

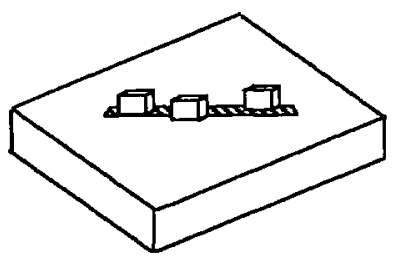

2) $\mathrm{SrTiO}_{3}$ buffer layer

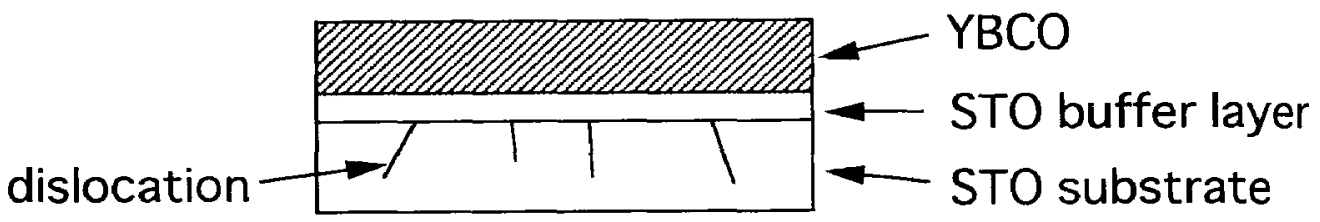

3) Preventing exposure of $\mathrm{Cu}$ atoms to the substrate

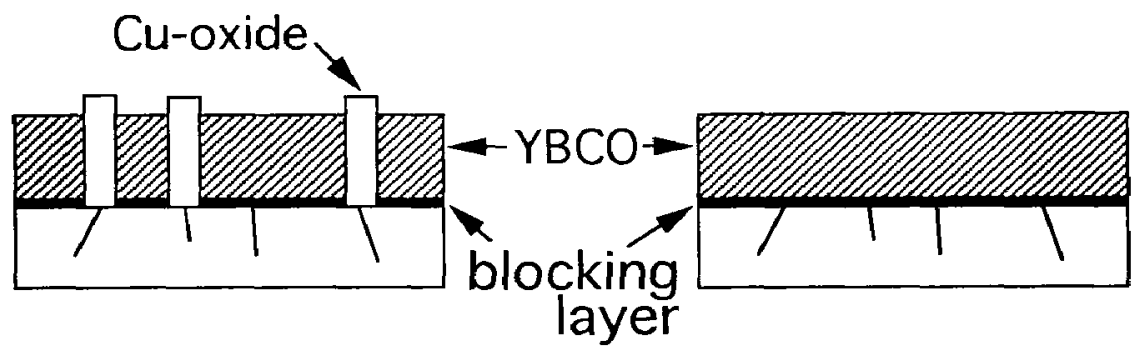

4) Sweeping away by STM tip

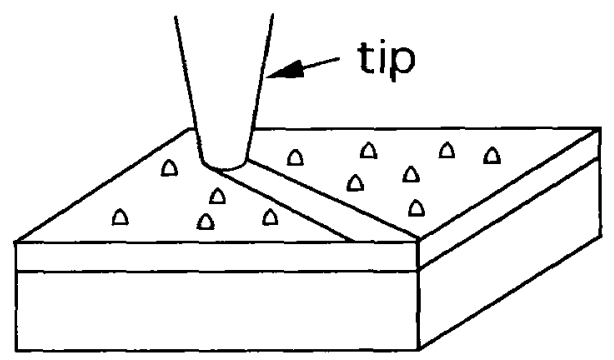

Figure 5: Methods for eliminating boulders from the surface of YBCO prepared by MOCVD.

(1) Engraved artificial getter on the substrate. (2) STO epitaxial buffer layer on STO substrate. (3) Blocking layer. (4) Sweeping away by STM tips. 


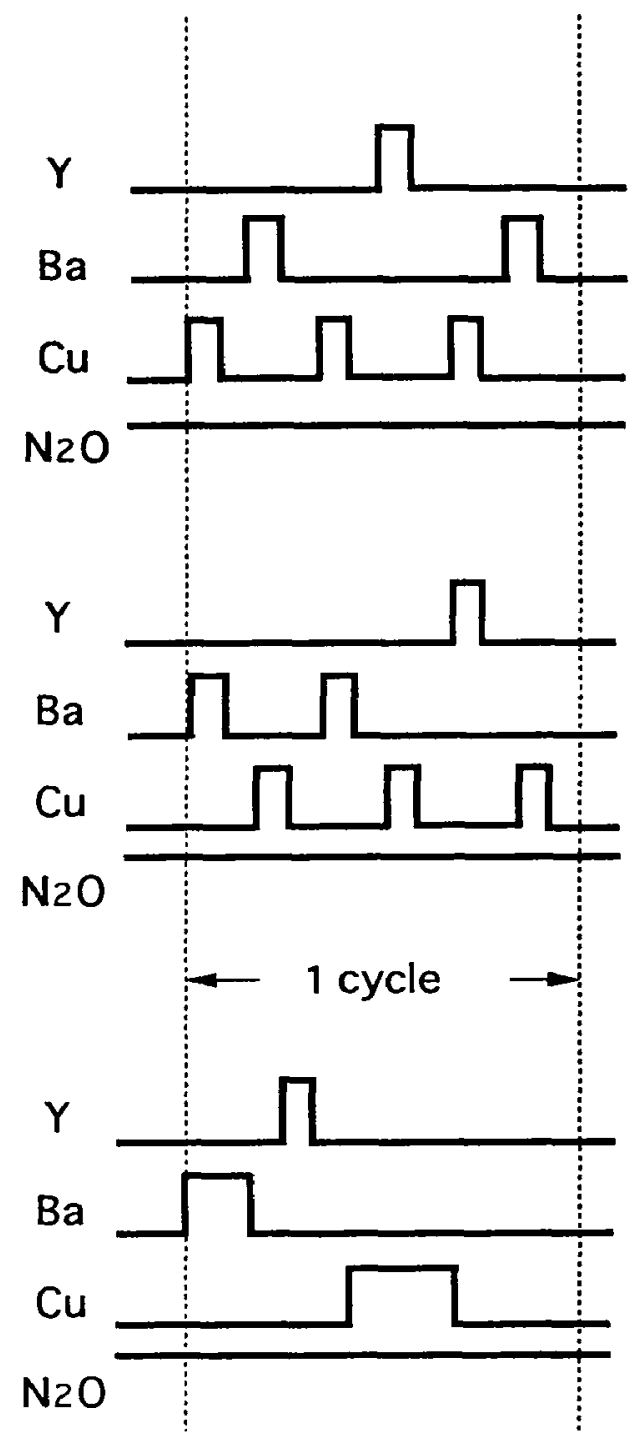

(a)

(b)

(c)

Figure 6: Sequential timing of gas source supply. (a) Atomic layer-by-layer method start with $\mathrm{Cu}$. (b) Atomic layer-by-layer method start with Ba. (c) Block-by-block method.

We will focus the third method by taking advantage of atomic layer-by-layer deposition. We have already reported that when we start the gas supply with $\mathrm{Cu}$ (Fig. 6(a)), the film is rich in the second phase [6]. It is necessary to start with Ba atomic layer (Fig. 6(b)) to obtain films with limited number of the second phase. $\mathrm{BaO}$ is not stable and change to $\mathrm{YBCO}$ after one cycle of gas source supply is completed. In order to minimize the chance of contact between $\mathrm{Cu}$ atoms and substrate, a block-by-block deposition cycle is proposed. Locquet et al deposited thin films of Dysprosium-123 system by a block-by-block mode (Fig. $6(c))$ in MBE and successfully controlled the second phase precipitates over $6 \mu \mathrm{mx} 6 \mu \mathrm{m}$ [7]. We too have preparcd YBCO tilms by block-by-blexk MOCVD. We could not find the boulders from this sample orer $25 \mu \mathrm{m} \times 25 \mu \mathrm{m}$ as shown in Fig. $7(\mathrm{~b}))$. 

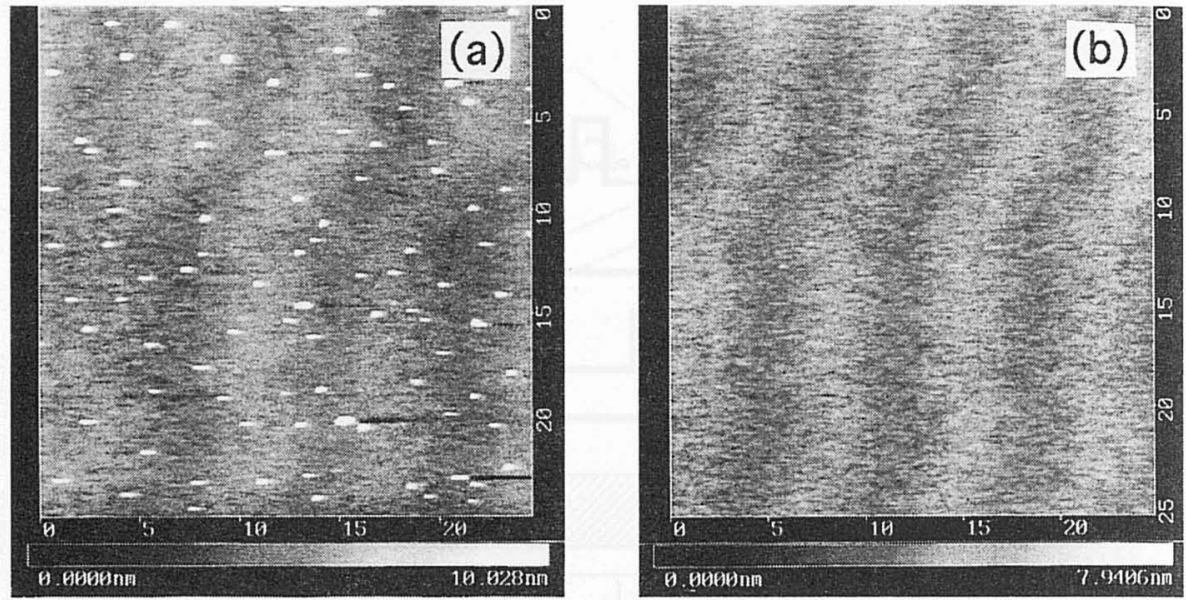

Figure 7: AFM images of surface of YBCO films prepared by (a) atomic layer-by-layer MOCVD and (b) block-by-block MOCVD. The area is $25 \mu \mathrm{m} \times 25 \mu \mathrm{m}$.
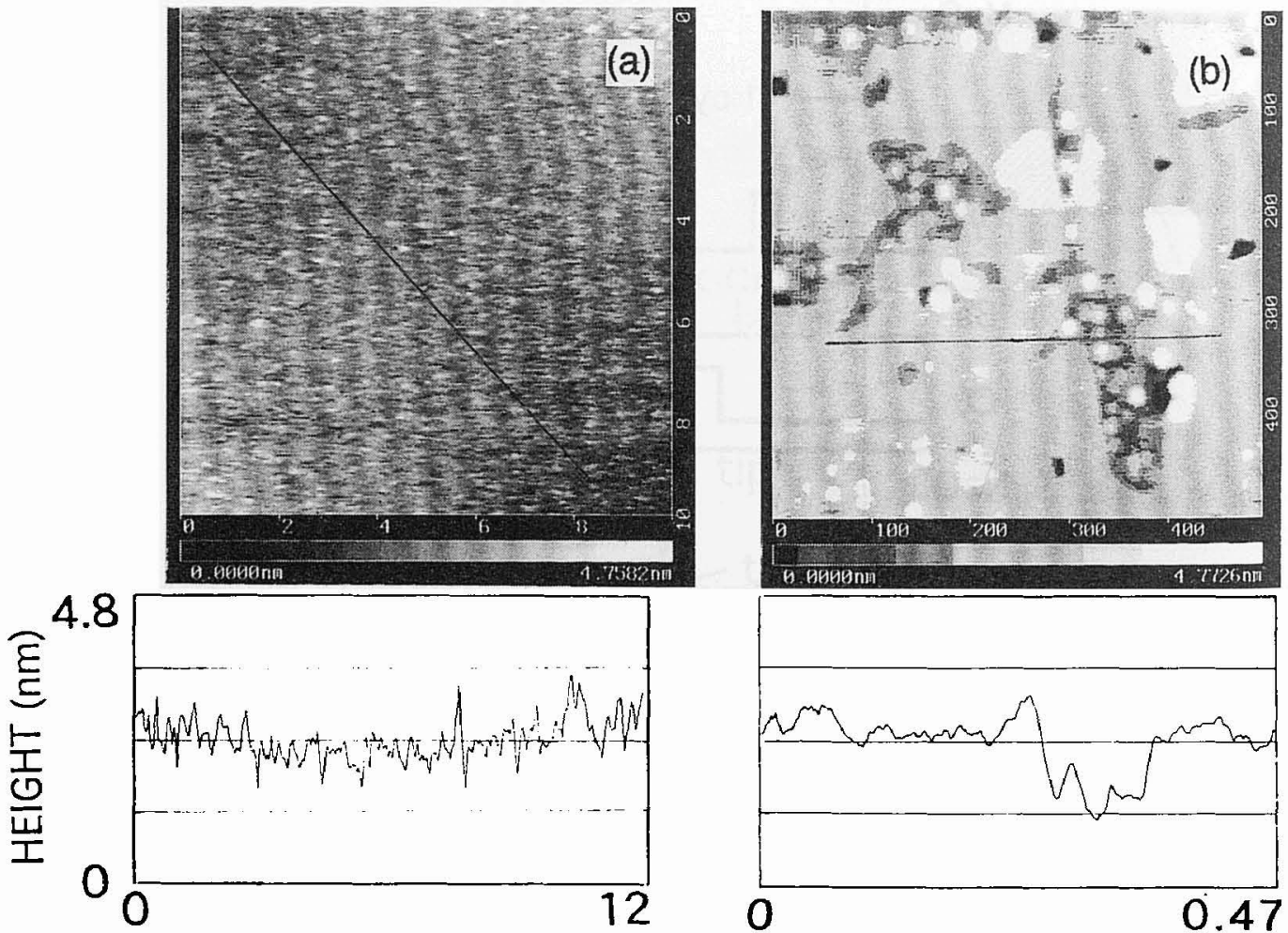

\section{DISTANCE $(\mu \mathrm{m})$}

Figure 8: $\mathrm{AFM}$ images of surlace of a YBCO film prepared by atomic layer-by-layer MOCVD on an STO substrate. The arca is (a) $10 \mu \mathrm{mx} 10 \mathrm{~mm}$ and (b) $500 \mathrm{~mm} \times .500 \mathrm{~nm}$. 


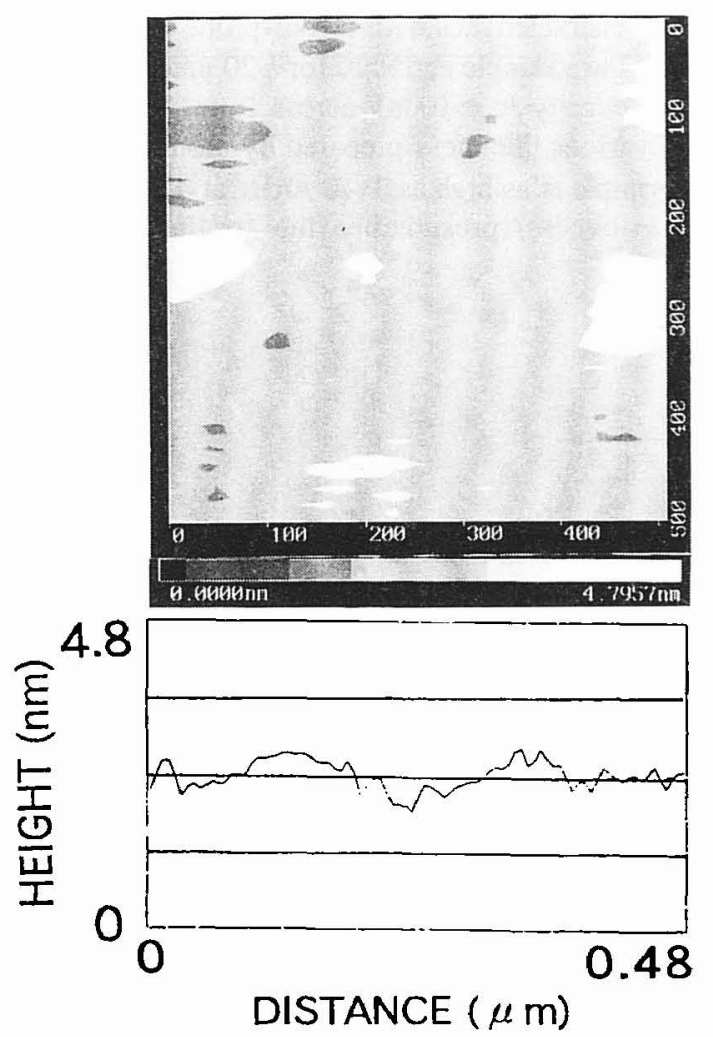

Figure 9: AFM images of surface of a YBCO film prepared by atomic layer-by-layer MOCVD on an NGO substrate. The area is $500 \mathrm{~nm} \times 500 \mathrm{~nm}$.

Even when we deposit films by atomic layer-by-layer MOCVD, we could control the precipitates as long as we could make pin-hole-free layer as the first $\mathrm{BaO}$ layer. A 10 unit-cell-thick YBCO film with free of precipitates over $10 \mu \mathrm{m} \times 10 \mu \mathrm{m}$ was obtained as shown in Fig. 8(a). The roughness is less than one unit-cellthick. We could see a step of $1.2 \mathrm{~nm}$ with a terrace width of $330 \mathrm{~nm}$ in the case of STO substrate. In order to increase the flat area, we used NGO substrate whose lattice matched with YBCO better than STO. We have obtained YBCO films with terrace width of $660 \mathrm{~nm}$. When we compare the results between STO and NGO substrate with the same scale, the performance of NGO substrate is clear as shown in Fig. 9. This result is very promising for S-I-S tri-layer devices.

The terrace width of best films obtained by PLD, sputtering or conventional MOCVD is about 100nm. Why does MOCVD provide a very smooth surface of YBCO? Endo prepared very smooth surface in Bi-system by MOCVD at a very slow speed of $1 \mathrm{~nm} /$ hour. [8] Scheel prepared very flat YBCO films by liquid phase epitaxy and claimed that the terrace width was Ionger than $10 \mu \mathrm{m}$. [9] He cxplains that the reason why LPE films are flat is that LPE is close to thermal equilibrium condition contrary to PVD and CVD. However, we think that MOCVD is quasi-equilibrium condition near the substrate particularly when deposition rate is very low. 
We have measured superconducting characteristics with a four-probe electrode configuration. The critical temperature is $80 \mathrm{~K}$ for a 10 unit-cell-thick sample and $85 \mathrm{~K}$ for a 20 unit-cell-thick sample as shown in Fig. 10. Our criteria of the critical current density $\mathrm{Jc}$ is $100 \mathrm{nV}$ across $1 \mathrm{~mm}$. Figure 11 shows $\mathrm{Jc}$ as a function of temperature for YBCO films with various thickness prepared by atomic layer-by-layer MOCVD on STO substrates. The Jc for $40 \mathrm{~nm}$-thick sample is as high as $3 \times 10^{7} \mathrm{~A} / \mathrm{cm}^{2}$ at $4.2 \mathrm{~K}$ and $3 \times 10^{6} \mathrm{~A} / \mathrm{cm}^{2}$ at $77 \mathrm{~K}$. The $\mathrm{Jc}_{\mathrm{C}}$ decreases with decreasing film thickness, presumably due to the degradation during wet etching process.[10,11]

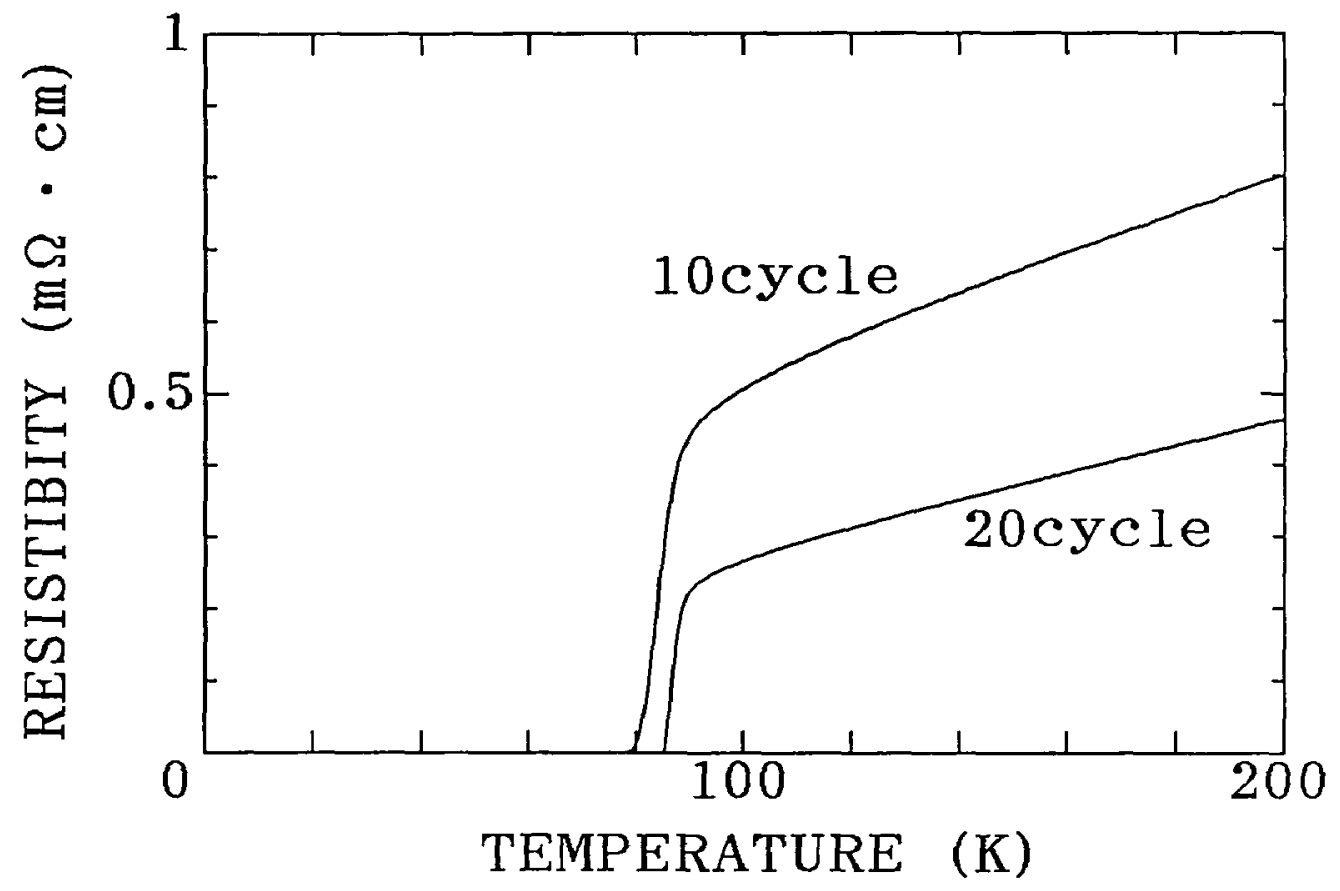

Figure 10: Resistivity-temperature characteristics for YBCO films prepared by atomic layer-by-layer MOCVD on STO substrates for 10 cycles and 20 cycles of gas source supply. 


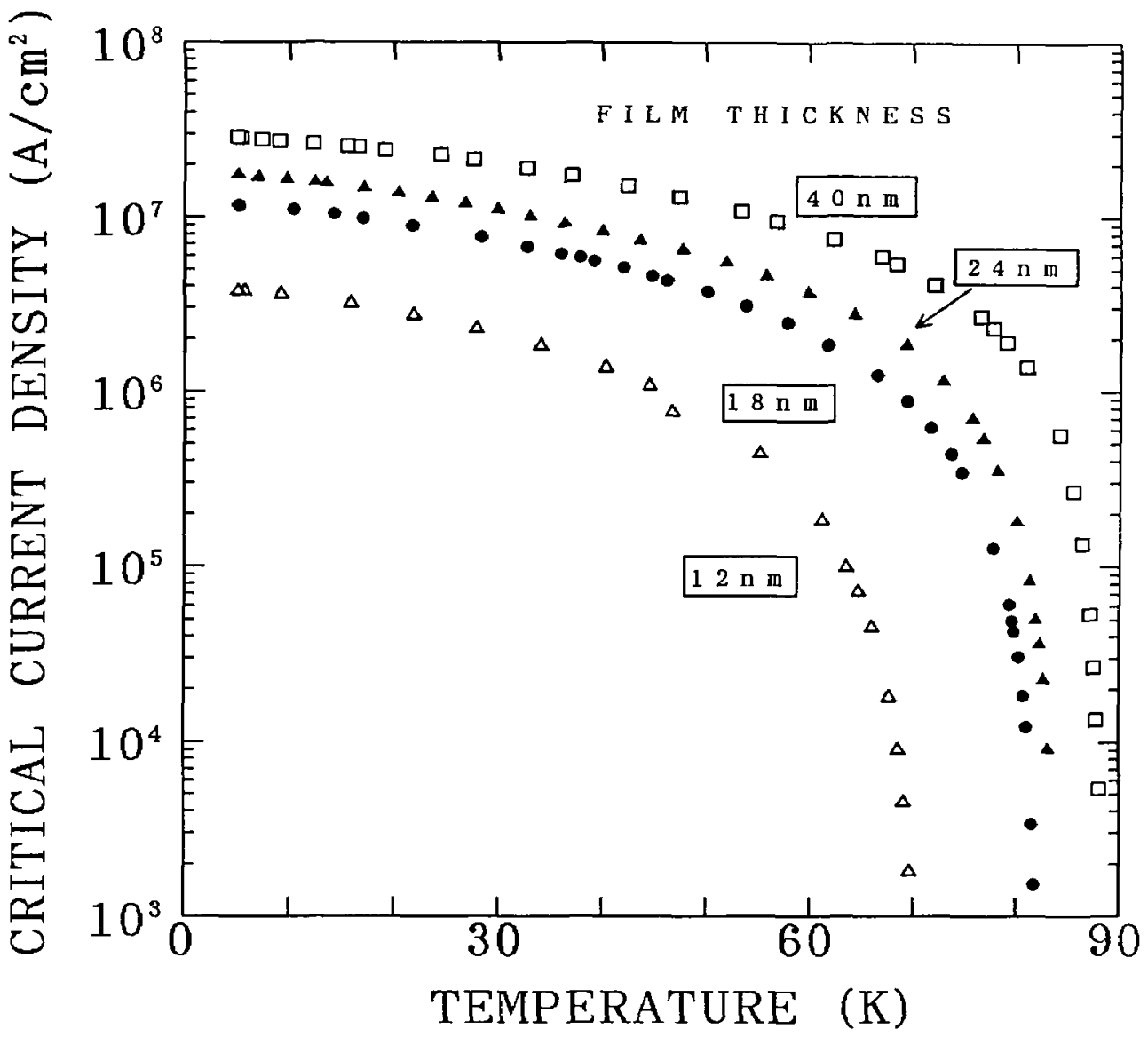

Figure 11: Superconductivity critical current density as a function of temperature for YBCO films prepared by atomic layerby-layer MOCVD on STO substrates with various thicknesses.

\section{SUMMARY AND CONCLUDING REMARKS}

Very smooth surface films of c-axis oriented YBCO with roughness of less than monomolecular layer over $10 \mu \mathrm{mx} 10 \mu \mathrm{m}$, free of precipitates, have been obtained by atomic layer-by-layer MOCVD on SrTiOz and $\mathrm{NdGaO}_{3}$ substrates at $650^{\circ} \mathrm{C}$. A very large terrace length of $0.3 \mu \mathrm{m}$ for films on $\mathrm{SrTiO}_{3}$ and $0.7 \mu \mathrm{m}$ for films on $\mathrm{NdGaO}_{3}$ may be due to the enhanced migration of growing species on the surface. The correlation between boulder formation and dislocations in the substrate is clarified. Several methods to prepare boulder-free films are proposed. The important thing in eliminating boulders is to block the contact of $\mathrm{Cu}$ atoms to dislocations on the surface of the substrate. Very high critical current densities of $3 \times 10^{7} \mathrm{~A} / \mathrm{cm}^{2}$ at $4.2 \mathrm{~K}$ and $3 \times 10^{6} \mathrm{~A} / \mathrm{cm}^{2}$ at $77 \mathrm{~K}$ have bcen obtained. These films are promising for the application of S-I-S trilayer junctions and ficld effect devices.

The advantage of atomic layer-by-layer MOCVD has been demonstrated for the preparation of very flat films of YBCO free of boulders. The present method is very time consuming process. The deposition rate can be increased by employing fast residence time system and fast response valves together with higher substrate temperature. The question is whether very llat films are obtaincd even at a last process. 
The feature that chemical purification takes place on the growing surface in MOCVD allows a wide margin for gas source supply rate compared with PVD methods. The second generation precursors for MOCVD of oxide superconductors improved reproducibility of MOCVD process significantly. However, more reproducible process is required for manufacturing superconducting devices. The third generation precursors with liquid phase at operating temperatures will be helpful for a stable gas source supply avoiding the problem of sintering in the case of solid phase precursors. Monitoring of precursor concentrations during deposition using ultrasonic or ultraviolet absorption will also be useful for improving reproducibility.

\section{Acknowledgments}

This work was supported in part by a Grant-in-Aid for Scientific Research from the Ministry of Education, Science and Culture, by NEDO under the management of FED, and by the Yazaki Memorial Foundation.

\section{References}

[1] Oda S., Bull. Electrotechnical Lab. 58 (1994) 107-111.

[2] Oda S., Sakai K. and Zama H., Appl. Surf. Sci. 75 (1994) 259-262.

[3] Oda S., Zama H. and Yamamoto S., J. Cryst. Growth 145 (1994) 232-236.

[4] Oda S. et al., Thin Solid Films 225 (1993) 284-287.

[5] Kobayashi N. et al., Jpn. J. Appl. Phys. 24 (1985) L962-L964.

[6] Fujii K., Zama H. and Oda S., Jpn. J. Appl. Phys. 31 (1992) L787-L789.

[7] Locquet J-P. et al., Appl. Phys. Lett. 64 (1994) 372-374.

[8] Endo K. et al., HTSED Workshop '94 Co-Sponsored by FED and NIST, (1994) pp. 94-95.

[9] Scheel H.J., Advances in Superconductivity VI, edited by T. Fujita and Y. Shinohara, (Springer, 1994) pp. 29-36.

[10] Oda S., Zama H. and Yamamoto S., IEEETrans. Appl. Superconductivity, at press.

[11] Yamamoto S., Kawaguchi A. and Oda S., Advances in Superconductivity VII, (Springer, 1995) at press. 